Simpson's patent all-bright anti-dazzle

This content has been downloaded from IOPscience. Please scroll down to see the full text. 1922 Trans. Opt. Soc. 23285

(http://iopscience.iop.org/1475-4878/23/4/316)

View the table of contents for this issue, or go to the journal homepage for more

Download details:

IP Address: 128.111.121.42

This content was downloaded on 28/08/2015 at 01:10

Please note that terms and conditions apply. 
reflector to which it is to be fitted. The front reflector is placed in the lamp so as to be co-axial with the back reflector, its lower edge just hiding the filament of the lamp, thus obviating the possibility of direct rays from the filament reaching the eye.

In order to obtain a divergent beam the filament must of course be behind the focus of the back reflector. This causes dazzle by the intensity of the light which reaches the eye from the upper half of the reflector. The device under consideration collects this light and redirects it in a useful direction, viz. on to the surface and sides of the road and into the beam thrown ahead. The rays which would cause

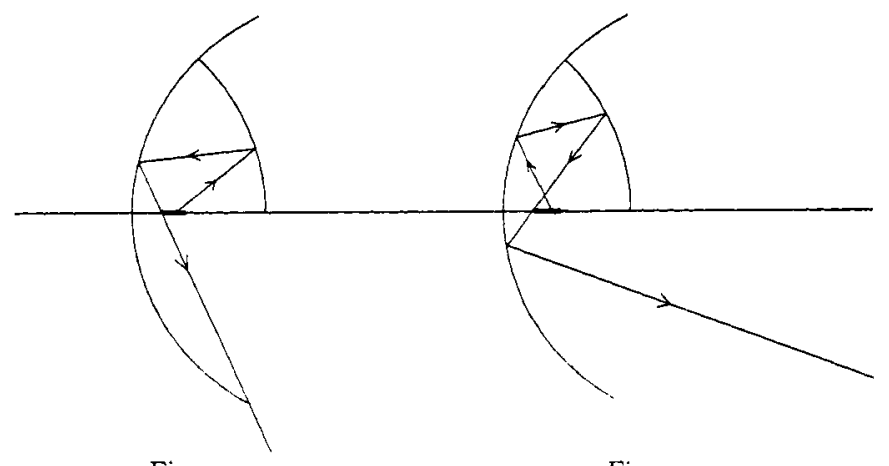

Fig. I

Fig. 2

dazzle (when no part of the filament is in front of the focus), as shown in Figs. I and 2 , are therefore trapped and redirected so as to intensify the light where required, no light at all being sacrificed. All rays which reach the lower half of the back reflector directly from the lamp are thrown downwards by virtue of the fact that the beam is divergent.

A wise choice of filament is, of course, essential and it is obvious that the best results will be obtained from one which lies as nearly as possible along the axis.

The Electric Repair and Lighting Co. of Reading, has now completed arrangements for the production of the device, which is provisionally patented and can be fitted to any standard electric headlamp.

\section{SIMPSON'S PATENT ALL-BRIGHT ANTI-DAZZLE}

\section{By H. J. SIMPSON.}

THE function of this device is to overcome the spreading of the rays from ordinary motor car and cycle headlamps, whether acetylene or electric. It consists of a number of plated slats, of prismatic cross-section, arranged at such an angle that the upward rays from the reflector are reflected from the inner face of one slat to the outer face of the neighbouring slat and thence in a horizontal direction outwards. The slats extend a fraction of an inch below the optical axis of the lamp and an additional thin slat is fixed near the bottom of the lamp so as to deflect the upward rays from the bottom of the reflector on to the road. The slats are carried in two 
plated vertical members which also serve to reflect the side rays on to the slats and thence forwards.

With this anti-dazzle there is no direct glare to "blind" temporarily the vision of either drivers or pedestrians. No dimming switches are required and there are no levers to attend to.

The device tends to increase slightly the amount of light thrown on the road. It is very simple and can be made to fit any size or type of headlamp.

\section{DESCRIPTION OF KEN'T'S GLARE GUARD}

\section{By MessRS GEORGE KENT, LTd.}

THIS consists of a rectangle of glass of a smoked blue tint that effectually shades the eyes from the blinding rays of headlights. The glass is held in a frame which pivots about the upper edge, and is clipped to the glass or beading of the wind-screen before the driver. The correct position for the guard is slightly to the right of the driver's line of sight when looking ahead and the recommended method of using the glare guard is to keep it interposed between the eyes and the headlights of approaching cars while at the same time looking past the guard, not through it, at the road ahead.

The Royal Automobile Club Demonstration No. 6 proved that the use of the guard increased the "no-dazzle" space between the offending lamps and an approaching driver from 129 feet to 268 feet.

\section{DISCUSSION}

Commander T. Y. Baker: As Mr Walsh has so clearly stated in his paper, the problem of the motor headlight is two-fold. The motorist needs enough illumination to light up obstructions in the road for a sufficient distance so that he may pull up in time; the pedestrian, the man on the push bicycle, or the driver of an opposing car does not want to be dazzled by the glare. The driver needs at least 3000 candles, the man in the other car is blinded by less than a quarter of this.

I think it may be stated without fear of contradiction that the man driving behind the headlights has received from inventors and designers much more attention than the victim of glare. The natural candle power of lamps and the efficiency of reflectors have been increased to such an extent that it is now a common occurrence to meet upon the road cars with headlights whose effective candle power in a horizontal direction is ten to fifteen thousand. In only a minute fraction of the number of lamps of this character is there any attempt to keep the glare effect below the horizontal and my own experience of having to drive a small car fifteen miles every day after dark during the winter months on one of the main roads out of London is that with private cars and motor bicycles coming in the opposite direction one is dazzled by the light from 80 per cent. of them; with commercial 